\title{
Assay and recommendations for the detection of vapour- phase-mediated antimicrobial activities
}

\author{
Adam F. Feyaerts $^{1,2}$ (1) | Lotte Mathé ${ }^{1,2}$ () | Walter Luyten ${ }^{3}$ | Hélène Tournu ${ }^{1,2}$ | \\ Katrien Van Dyck ${ }^{1,2}$ | Lize Broekx ${ }^{1,2}$ | Patrick Van Dijck ${ }^{1,2}$
}

${ }^{1}$ VIB-KU Leuven Center for Microbiology, KU Leuven, 3001 Leuven, Belgium

${ }^{2}$ Laboratory of Molecular Cell Biology, KU Leuven, 3001 Leuven, Belgium

${ }^{3}$ Department of Biology, KU Leuven, 3000 Leuven, Belgium

\section{Correspondence}

Patrick Van Dijck, Laboratory of Molecular Cell Biology, KU Leuven, VIB-KU Leuven Center for Microbiology, Kasteelpark Arenberg 31 bus 2438, 3001 Heverlee, Belgium.

Email: patrick.vandijck@kuleuven.vib.be

Funding information

Fund for Scientific Research Flanders, Grant/ Award Number: FWO projects WO.009.16 N and G0D4813N

\begin{abstract}
Antimicrobial activity assays can be carried out in aqueous solutions using multi-well plates. However, some bioactive compounds are volatile and can cause effects at a distance. To detect such vapour-phase-mediated antimicrobial activity, we introduce the vapour-phase-mediated patch assay, a simple bioassay that uses standard microtitre plates. As a proof-of-principle, we use the vapour-phase-mediated patch assay to test a small but chemically diverse set of selected essential oils with known antifungal activities i.e. Origanum compactum, Artemisia dracunculus, Cinnamomum camphora ct linalool, Cinnamomum cassia and Melissa officinalis, as well as their corresponding major components carvacrol, estragole, linalool, trans-cinnamaldehyde and citral, against two pathogenic Candida species. As all but one of the tested essential oils i.e. Artemisia dracunculus and its corresponding component estragole, showed vapour-phase-mediated antimicrobial activity, we conclude that it is a rather common characteristic of essential oils and their components, that should always be taken into consideration. Additionally, we provide suggestions to prevent false positive results due to possible vapour-phase-mediated antimicrobial activities in bioactivity tests.
\end{abstract}

\section{KEYWORDS}

bioassay, Candida species, essential oil, essential oil component, vapour-phase-mediated antimicrobial activity

\section{1 | INTRODUCTION}

The treatment of multi-resistant microorganisms is increasingly difficult, making the discovery of new antimicrobials urgent and imperative. To this purpose, large compound libraries that aim to cover a wide range of the chemical space are typically screened..$^{1-4} \mathrm{~A}$ wide variety of methods are available for testing antimicrobial activities in vitro, summarized recently by Balouiri et al. (2016). ${ }^{5}$

The potency of a molecule against a microorganism is typically expressed as its minimal inhibitory concentration (MIC) i.e. the lowest concentration necessary to cause a specified reduction in (visible) growth. ${ }^{6}$ Although different set-ups are possible, the MIC is mostly determined in multi-well plates because this format yields reliable

Adam F. Feyaerts and Lotte Mathé contributed equally to this study.

This article is part of the special issue of the Flavour and Fragrance Journal entitled "47th International Symposium on Essential Oils (ISEO)" edited by Nicolas Baldovini. results with limited resources. In addition, standardized protocols are preferred to increase reproducibility and permit comparison between experiments. ${ }^{5}$ However, determining the MIC for molecules with a relatively high vapour pressure can be challenging as these volatiles tend to evaporate over the course of the assay. This may lead to underestimation of the activity in the well containing the compound, and spurious activity in adjacent wells. To limit loss due to evaporation and to limit interference, the microtiter plates could be sealed, although this is not always possible or effective, nor desirable. Furthermore, standard screening protocols and MIC assays do not take vapour-phase-mediated effects of volatiles into account, which therefore mostly remain unnoticed.

Volatiles are typically enriched in essential oils (EOs), several of which are known for their antimicrobial activity against a wide variety of microorganisms including multi-resistant strains. ${ }^{7-12}$ Different assays are available to test the antimicrobial activity of the vapour-phase of volatiles. ${ }^{5,12-16}$ However, they mostly focus on the direct activity of the vapour-phase, and do not account for the vapour-phase-mediated 
effect, which is defined as the effect of a compound in solution at a distance.

In this study, we introduce the vapour-phase-mediated patch assay which is a simple assay for detecting the vapour-phase-mediated antimicrobial activity of EOs and their components (EOCs), and other volatiles. It uses standard 96-well plates where a patch is defined as the set of wells in a (square) area surrounding one or more test wells. Moreover, we introduce an alternative microtitre plate set-up that can be used in accordance with standard broth microdilution protocols to easily unmask false-positive results caused by the volatility of $\mathrm{EO}(\mathrm{C}) \mathrm{s}$. As a proof-of-principle, we studied the vapour-phase-mediated antimicrobial activity of selected $\mathrm{EO}(\mathrm{C}) \mathrm{s}$ against two pathogenic yeast species, Candida albicans and C. glabrata, and compared this to their MIC and corresponding minimal fungicidal concentration (MFC). These Candida species are dominant members of the human mycobiome, ${ }^{17}$ and the most common pathogenic fungi in humans. ${ }^{18}$ Even though they belong to the same genus, they are genetically and phenotypically very different. ${ }^{19,20}$

\section{2 | EXPERIMENTAL}

\section{1 | Essential oils and essential oil components}

All EOs $(n=7)$ were purchased from Pranarôm International S.A. (Ghislenghien, Belgium) (Table 1$)$ and all EOCs $(n=5)$ from SigmaAldrich (Steinheim, Germany) (Table 2). Quality, origin and composition of the $\mathrm{EO}(\mathrm{C}) \mathrm{s}$ were certified by both companies. Chemical analysis of the EOs was performed by GC-FID using the NF ISO 11024-1/2 standard. The detailed compositional analyses are available in electronic supplementary material (SI 1-7).

The $\mathrm{EO}(\mathrm{C}) \mathrm{s}$ were aliquoted in sterile glass vials (Screening Devices, Amersfoort, the Netherlands) and coded to blind the experiments. Dimethyl sulfoxide 99\% (DMSO; Sigma-Aldrich) was used as a solvent if the $\mathrm{EO}(\mathrm{C})$ s were dissolved prior to testing, and as a corresponding control.
TABLE 2 List of highly enriched essential oil components

\begin{tabular}{lcll}
$\begin{array}{l}\text { Highly enriched essential oil } \\
\text { components }\end{array}$ & $\begin{array}{c}\text { Purity } \\
\text { (\%) }\end{array}$ & $\begin{array}{c}\text { Product } \\
\text { number }\end{array}$ & Lot number \\
\hline estragole & $\geq 98$ & A29208 & MKBR0582V \\
\hline carvacrol & $\geq 99$ & W224511 & MKBR8607V \\
\hline linalool & $\geq 97$ & L2602 & STBF6800V \\
citral $^{\#}$ & $\geq 95$ & C83007 & STBC5273V \\
\hline trans-cinnamaldehyde & $\geq 99$ & C80687 & MKBV8774V
\end{tabular}

\#a mixture of the isomers geranial and neral.

\section{2 | Candida albicans and Candida glabrata}

C. albicans strain SC5314 and C. glabrata strain ATCC 2001 were maintained on Yeast extract Peptone Dextrose (YPD) agar plates composed of $10 \mathrm{~g} / \mathrm{l}$ yeast extract (Merck, Darmstadt, Germany), $20 \mathrm{~g} / \mathrm{l}$ bactopeptone (Oxoid, Basingstone, UK), $20 \mathrm{~g} / \mathrm{l}$ glucose (Sigma-Aldrich) and $15 \mathrm{~g} / \mathrm{l}$ Difco $^{\mathrm{TM}}$ agar (Becton, Dickinson \& Co., Sparks, MD, USA). Prior to experiments the strains were grown overnight at $35^{\circ} \mathrm{C}$ on Sabouraud agar plates containing $47 \mathrm{~g} / \mathrm{I}$ Sabouraud agar (Sigma-Aldrich).

\subsection{Preparation of the cell inoculum}

A small loop of overnight propagated cells was suspended in $1 \mathrm{x}$ Phosphate-Buffered Saline (PBS) containing $8 \mathrm{~g} / \mathrm{l}$ sodium chloride (Sigma-Aldrich), $0.2 \mathrm{~g} / \mathrm{l}$ potassium chloride (VWR International, Leuven, Belgium), $1.44 \mathrm{~g} / \mathrm{l}$ disodium hydrogen phosphate (Merck), and $0.24 \mathrm{~g} / \mathrm{l}$ potassium dihydrogen phosphate (Merck). The cell density was estimated by measuring the Optical Density at $600 \mathrm{~nm}\left(\mathrm{OD}_{600}\right)$ with a biophotometer (Eppendorf, Hamburg, Germany) and the desired cell suspension was made in Roswell Park Memorial Institute-1640 (RPMI) medium (Sigma-Aldrich). This medium was buffered with 3-(N-morpholino) propanesulfonic acid (MOPS; Sigma-Aldrich) and filter-sterilised over a $0.20 \mu \mathrm{m}$ non-pyrogenic

TABLE 1 List of chemically defined essential oils with components ( $\geq 10 \%$ )

\begin{tabular}{|c|c|c|c|c|c|}
\hline Chemically defined essential oils & Part of plant & Place of origin & Lot number & Component(s) $\geq 10 \%$ (v/v) & $\%(v / v)$ \\
\hline Origanum compactum* & FT & Morocco & $\begin{array}{l}\text { OCH13 } \\
\text { (in Figure 1) } \\
\text { OF10299 } \\
\text { (in Figure 2) }\end{array}$ & $\begin{array}{l}\text { carvacrol } \\
\text { thymol } \\
\gamma \text {-terpinene } \\
\mathrm{p} \text {-cymene } \\
\text { carvacrol } \\
\text { thymol } \\
\gamma \text {-terpinene }\end{array}$ & $\begin{array}{l}39.95 \\
19.51 \\
16.23 \\
10.86 \\
43.67 \\
19.52 \\
16.16\end{array}$ \\
\hline Pimenta racemosa & $\mathrm{F}$ & Antilles & PRS4 & $\begin{array}{l}\text { eugenol } \\
\beta \text {-myrcene } \\
\text { chavicol }\end{array}$ & $\begin{array}{l}45.23 \\
25.92 \\
10.60\end{array}$ \\
\hline Artemisia dracunculus & FT & France & OF10105 & $\begin{array}{l}\text { estragole } \\
\beta \text {-ocimene }\end{array}$ & $\begin{array}{l}79.36 \\
15.05\end{array}$ \\
\hline Cinnamomum camphora ct linalool & W & China & OF10369 & linalool & 98.35 \\
\hline Cinnamomum cassia & $\mathrm{T}$ & China & OF10584 & $\begin{array}{l}\text { trans-cinnamaldehyde } \\
\text { 2-methoxycinnamaldehyde }\end{array}$ & $\begin{array}{l}78.45 \\
10.75\end{array}$ \\
\hline Melissa officinalis & AP & Bulgaria & OF10300 & $\begin{array}{l}\text { citral } \\
\beta \text {-caryophyllene } \\
\text { germacrene D }\end{array}$ & $\begin{array}{l}36.76 \\
23.46 \\
11.52\end{array}$ \\
\hline
\end{tabular}

AP: aerial parts; F: fruit; FT: flowering top; T: twigs; W: wood.

${ }^{*}$ Different batches of the same essential oil.

${ }^{\#}$ A mixture of the isomers geranial and neral. 
Nalgene $^{T M}$ filter (Fisher Scientific, Merelbeke, Belgium) in accordance with Clinical and Laboratory Standards Institute (CLSI) guidelines. ${ }^{6}$

\section{4 | Vapour-phase-mediated patch assay}

To all wells of a 96-well microtitre plate with $\mathrm{U}$-shaped wells (Greiner Bio-One, Vilvoorde, Belgium) $200 \mu \mathrm{l}$ of a $5 \times 10^{3}$ cells $/ \mathrm{ml}$ inoculum was added, with the exception of the corner wells to which $200 \mu \mathrm{l}$ RPMI-MOPS was added and which served as blanks. In the middle of a squared patch containing 9 or 36 wells, the desired volume of an $E O(C)$ to be tested was added either on top of the cell suspension, or into the suspension if the $\mathrm{EO}(\mathrm{C}) \mathrm{s}$ were dissolved in DMSO. Wells located outside of the patch, and distant enough not to be affected by the $\mathrm{EO}(\mathrm{C}) \mathrm{s}$, served as internal negative controls. Optionally, half of the patch and corresponding control wells were sealed with an acetate Corning ${ }^{\circledR}$ Cap Mat (SigmaAldrich). Multiple $\mathrm{EO}(\mathrm{C}) \mathrm{s}$ were tested in different microtitre plates in one experimental run. For each run, a microtitre plate without $\mathrm{EO}(\mathrm{C}) \mathrm{s}$ was included as external negative control. The microtitre plates were covered with a lid and then statically incubated (Heraterm, TermoFisher Scientific, Aalst, Belgium) for 24 hours at $35^{\circ} \mathrm{C}$ while limiting atmospheric disturbances. Optical scans (Epson Perfection V600, Seiko Epson Corp, Nagano, Japan) of the microtitre plates were made, and the $\mathrm{OD}_{600}$ was measured with a multi-well plate reader (Synergy H1, BioTek Germany, Bad Friedrichshall, Germany) after resuspending the cells. Optionally, cells from each well were spotted onto YPD agar plates using a plate replicator (V\&P Scientific, San Diego, CA, USA). These YPD plates were incubated overnight, after which optical scans were made.

\section{5 | Broth microdilution assay followed by spot test}

The broth microdilution assays were performed in accordance with the CLSI protocol ${ }^{6}$ with few adaptations. Briefly, to all wells of a 96-well microtitre plate $100 \mu \mathrm{l}$ of a $1 \times 10^{4}$ cells/ml inoculum was added, with the exception of wells serving as blanks to which $200 \mu$ l RPMI-MOPS was added. For each $\mathrm{EO}(\mathrm{C})$ to be tested, a test solution was prepared by dissolving one part $E O(C)$ in eight parts ( $/ / v)$ DMSO. A two-fold serial dilution ranging from $0.25 \%(v / v) E O(C)$ to $0.0078 \%(v / v) E O(C)$ was prepared in RPMI-MOPS and $100 \mu \mathrm{l}$ of each dilution was added to the wells with cell suspension resulting in a final cell density of $5 \mathrm{x}$ $10^{3}$ cells $/ \mathrm{ml}$ and final $\mathrm{EO}(\mathrm{C})$ concentrations ranging from $0.13 \%(\mathrm{v} / \mathrm{v})$ to $0.0039 \%(\mathrm{v} / \mathrm{v})$. To wells serving as negative controls, $100 \mu \mathrm{l}$ of RPMI-MOPS was added resulting in a final cell density of $5 \times 10^{3}$ cells $/ \mathrm{ml}$. Plates were sealed with an acetate Corning ${ }^{\circledR}$ Cap Mat and incubated for 24 hours at $35^{\circ} \mathrm{C}$. The MIC was determined as the lowest concentration required for visible growth inhibition or was based on $\mathrm{OD}_{600}$ measurements with a multi-well plate reader after resuspending the cells. Optical scans of the microtitre plates were made and a spot test was performed as described above.

\section{3 | RESULTS AND DISCUSSION}

In an antimicrobial screening (data not shown) of more than one hundred EOs against different bacteria and yeasts using standard 96-well microtitre plates and 100-well honeycomb titre plates with lids, three phenomena were frequently observed. Firstly, in some microtitre plates there were patches of wells with reduced or no growth, even if some of those wells contained $\mathrm{EO}(\mathrm{C}) \mathrm{s}$ that were known to be inactive at the tested concentrations. Secondly, there was reduced or no cell growth in some negative controls adjacent to the wells containing $\mathrm{EO}(\mathrm{C}) \mathrm{s}$. The $\mathrm{EO}(\mathrm{C}) \mathrm{s}$ in the centre of the affected patches or next to the affected negative controls were often known for their strong antimicrobial activity. Thirdly, the cell growth in the negative control wells was inversely related to the overall quantity of $\mathrm{EO}(\mathrm{C}) \mathrm{s}$ in a microtitre plate. These phenomena occurred when the microtitre plates were covered with a lid with or without condensation rings, although they were more pronounced in the latter case. We hypothesized that the observed phenomena were caused by the vapour-phase-mediated antimicrobial activity of some of the $\mathrm{EO}(\mathrm{C}) \mathrm{s}$ under study.

Based on these antimicrobial screening results, we selected one EO with (Origanum compactum EO) and one EO without (Pimenta racemosa EO) vapour-phase-mediated antimicrobial activity (Table 1) and tested the hypothesis using the vapour-phase-mediated patch assay. Briefly, four times $20 \mu$ l of each EO was added to the centre four wells of a 36-well patch after which half of the patch was sealed, rendering these wells atmospherically inaccessible, before covering the plate with a lid. After 24 hours of incubation, cell growth was clearly affected in non-sealed wells in the patch adjacent to wells containing Origanum compactum EO (which has vapour-phase-mediated antimicrobial activity), but not in non-sealed wells adjacent to those containing Pimenta racemosa EO (which is devoid of vapour-phase-mediated antimicrobial activity). Growth was unaffected in all sealed wells, independent of the EO added and the position of the wells with respect to the EO added (Figure 1A). Cell growth in the sealed wells was indistinguishable from growth in internal negative control wells that were not sealed and that were located far enough from the centre wells so as not to be affected by the EOs, indicating that growth was not substantially affected by sealing the plate (Figure 1B). Together, these results provided a direct link between the presence of an EO with vapourphase-mediated antimicrobial activity and the inhibition of cell growth in adjacent wells that were not sealed.

However, the absence of vapour-phase-mediated antimicrobial activity on growth in nearby wells does not exclude possible effects of the tested EO on cells in surrounding wells. For instance: (i) the tested quantity of the EO may be subinhibitory, meaning that higher quantities might still affect cell growth in surrounding wells, (ii) an endpoint measurement may not be sufficient to detect an effect on cell growth such as a lag phase extension, which could be solved by measurements during the incubation, or (iii) the effects on the cells in nearby wells may not be growth-related but linked to for example the phenotype e.g. induction or repression of hyphal growth, which could be revealed by microscopy.

As a proof-of-principle, we selected five commercially available and chemically diverse EOs (Table 1 ) each rich in one specific EOC and known for its antimicrobial potential, as well as their corresponding commercially available EOCs (Table 2). Their MIC and MFC against a strain of both $C$. albicans and C. glabrata (Table 3), yielding values of $\leq 0.13 \%(v / v)$ for most EO(C)s. For Cinnamomum camphora ct linalool 
(A)
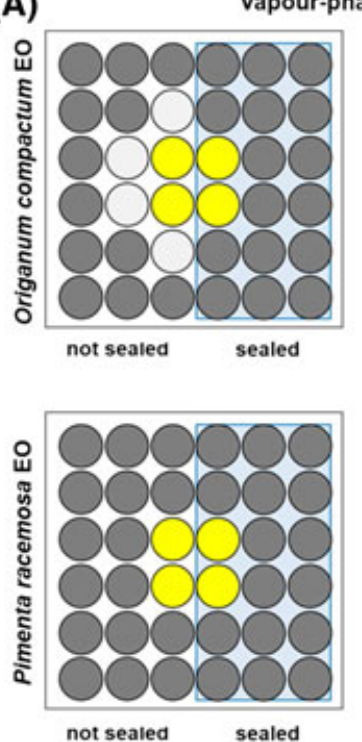

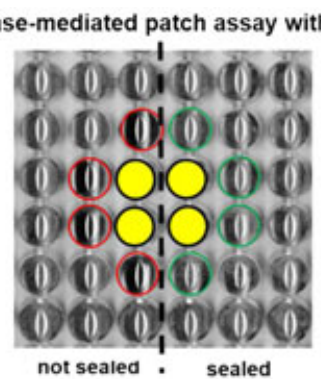

I

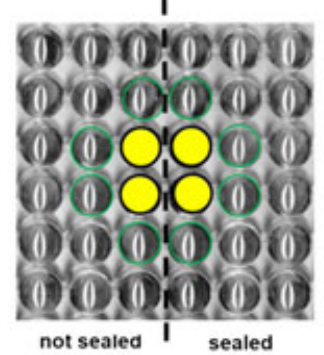

36-well patch
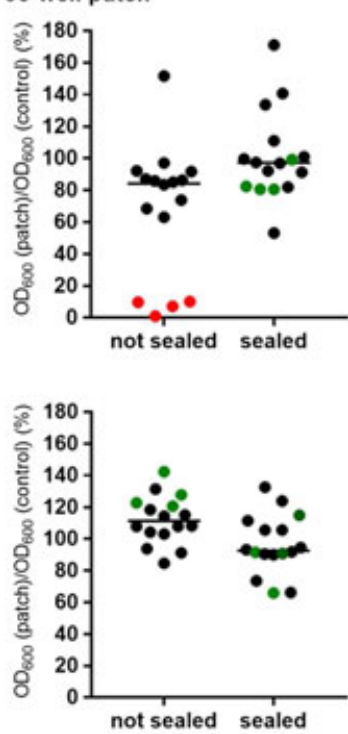

internal
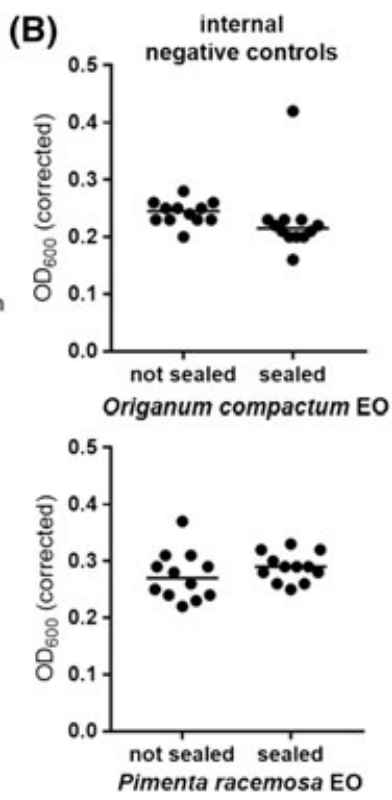

FIGURE 1 The vapour-phase-mediated antimicrobial activity of EOs affects C. albicans cell growth (24 h) in adjacent wells that were not sealed. A: Schematic illustration (left column), optical scan of microtitre plate (second column) and OD measurements (right columns) of the vapour-phasemediated patch assay showing the effect of Origanum compactum EO with vapour-phase-mediated antimicrobial activity (upper panels) and Pimenta racemosa EO without vapour-phase-mediated antimicrobial activity (lower panels) on growth of $C$. albicans cells in the wells of the patch. B: Comparison of cell growth (OD measurements) in negative control wells (not sealed and sealed)

TABLE 3 Minimal inhibitory concentration and minimum fungicidal concentration of the $E O(C)$ s under study against $C$. albicans and $C$. glabrata $(24 \mathrm{~h})$

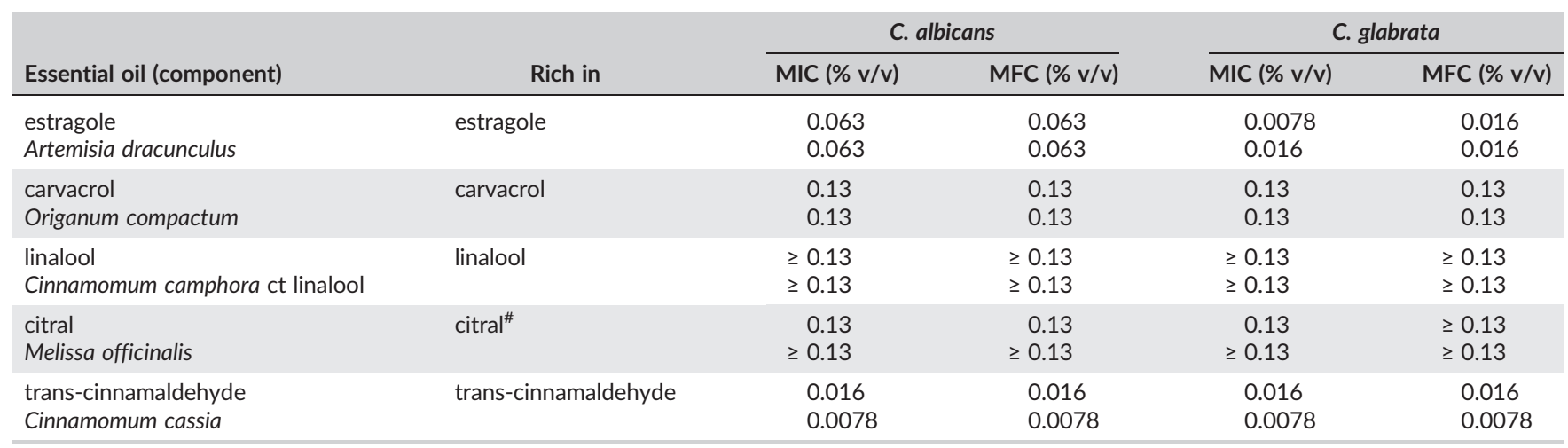

${ }^{\#} \mathrm{~A}$ mixture of the isomers geranial and neral.

EO, Melissa officinalis EO and linalool EOC the MIC could not be determined as $0,13 \%(v / v)$ was the highest concentration that could be tested in this experimental set-up due to cytotoxicity of the solvent DMSO. However, the anti-Candida activity of these EOs has been described before. ${ }^{7,21,22}$

We then tested if these $\mathrm{EO}(\mathrm{C})$ s had vapour-phase-mediated antimicrobial activity against either Candida species. Moreover, we included the commonly used antifungals fluconazole, caspofungin, amphotericin B, 5-flucytosine and terbinafine. To determine whether each of the observed vapour-phase-mediated antimicrobial activities was also fungicidal, in addition to inhibiting cell growth, spot tests were performed. We did not observe inhibitory or cidal vapour-phase-mediated antimicrobial activity for any of the above mentioned antifungals when added at a concentration five to ten times their MIC (data not shown). On the other hand, several of the tested EO(C)s showed vapour-phase-mediated antimicrobial activity, often both inhibitory and fungicidal. A representative selection of results is shown as an illustration (Figure 2), along with negative controls in which no EO(C) was added to the centre of the patches. Some $\mathrm{EO}(\mathrm{C})$ s were cidal when tested at volumes as small as $0.25 \mu \mathrm{l}$ (carvacrol and transcinnamaldehyde-rich EO of Cinnamomum cassia), while others had no effect on cell growth in adjacent wells even at volumes as high as $64 \mu \mathrm{l}$ (estragole and estragole-rich EO of Artemisia dracunculus) (Figure 2).

Moreover, these results show concordance between the vapourphase-mediated antimicrobial activity exhibited by a component and an EO rich in this component. However, even when tested on the same species, the results between the EO and its corresponding major EOC may not match exactly for instance because the amount of EOC may differ between the EO versus EOC, and/or the effect of other compounds with vapour-phase-mediated antimicrobial activity present in the EO. We demonstrated that the chemically diverse EOCs carvacrol, 


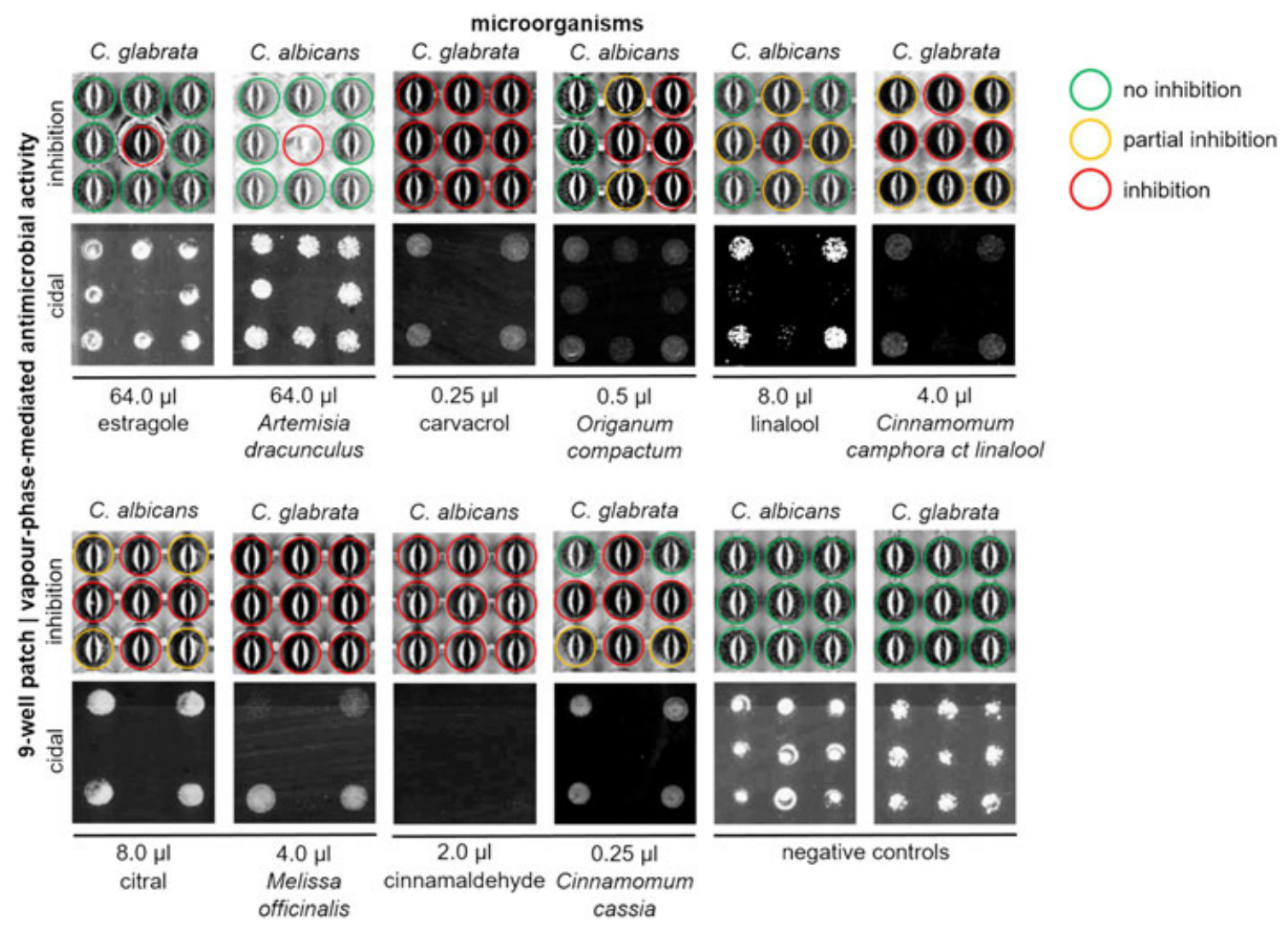

FIGURE 2 Different $\mathrm{EO}(\mathrm{C})$ s show inhibitory and fungicidal vapour-phase-mediated antimicrobial activity against two Candida species. Optical scans of 9-well patches of microtitre plates (top rows) and YPD agar plates with spot tests (bottom rows) showing growth inhibition and cidal activity, respectively, caused by the vapour-phase-mediated antimicrobial activity of selected EO(C)s on C. albicans and C. glabrata. Volume below YPD agar plates with spot tests indicates quantity of $\mathrm{EO}(\mathrm{C})$ added to the centre well

citral, trans-cinnamaldehyde and linalool, and EOs rich in these EOCs, exhibit vapour-phase-mediated antimicrobial activity against both Candida species tested. Direct vapour-phase antimicrobial activities were shown before for citral-, carvacrol- and linalool-rich EOs and their corresponding EOCs using different assays. ${ }^{21,23,24}$ Taking the variability of EO composition ${ }^{25,26}$ into account, this demonstrates that there is a degree of overlap between the direct vapour-phase antimicrobial activity and the vapour-phase-mediated antimicrobial activity measured here. Moreover, it indicates that reliable results can be obtained using the assay that we introduced. All EO(C)s tested have in common that they have a relatively low MIC. However, a low MIC does not automatically result in vapour-phase-mediated antimicrobial activity. The MIC of both Artemisia dracunculus EO and its main component estragole was relatively low while no vapour-phasemediated antimicrobial activity was observed even at volumes as high as $64 \mu \mathrm{l}$.

Since $\mathrm{EO}(\mathrm{C}) \mathrm{s}$ are frequently dissolved in DMSO before testing, we explored whether this affected their vapour-phase-mediated antimicrobial activity. Although DMSO itself had no vapour-phase-mediated antimicrobial activity, the vapour-phase-mediated antimicrobial activity of most of the tested $\mathrm{EO}(\mathrm{C}) \mathrm{s}$ that were dissolved in DMSO was still present, albeit attenuated (Figure 3).

A comparable effect was shown in a study on the antimicrobial activity of the EO of Cinnamomum zeylanicum on the yeast Saccharomyces cerevisiae using a broth microdilution assay. The antimicrobial activity was shown to be diminished after dissolving the EO in
DMSO, compared to using the EO pure. The researchers suggested that this was caused by the partitioning of the EO between the aqueous phase and DMSO, thus occluding the EO from the cells. ${ }^{27}$ It is conceivable that $\mathrm{EO}(\mathrm{C}) \mathrm{s}$ are contained by DMSO in the aqueous environment which would limit their evaporation hence resulting in an attenuated vapour-phase-mediated antimicrobial activity. However, since it seems difficult to predict whether DMSO will affect vapour-phase-mediated antimicrobial activity, we recommend to avoid using DMSO as a solvent in the vapour-phase-mediated patch assay.

Together, these results demonstrate that EOs with a diverse chemical composition, and their main EOCs, showed vapour-phasemediated antimicrobial activity at $\mu \mathrm{l}$ volumes, both when added pure and when dissolved in DMSO (Figures 2 and 3). Therefore, when performing antimicrobial screenings with $\mathrm{EO}(\mathrm{C}) \mathrm{s}$, the vapour-phasemediated antimicrobial activity must be taken into account as typically one or more $\mathrm{EO}(\mathrm{C}) \mathrm{s}$ are tested in the same microtitre plate. Moreover, if $\mathrm{EO}(\mathrm{C}) \mathrm{s}$ can affect the growth in adjacent wells, it is plausible that testing several $\mathrm{EO}(\mathrm{C}) \mathrm{s}$ in the same microtitre plate can affect multiple or even all wells.

MIC measurements of $\mathrm{EO}(\mathrm{C}) \mathrm{s}$ typically follow procedures described in reference methods (e.g. by CLSI), although adaptations are often applied. A commonly used adaptation to contain the EO(C)s in the wells is sealing the microtitre plates, which could also be a valid strategy to prevent $\mathrm{EO}(\mathrm{C})$ cross-contamination. However, at the same time it eliminates air circulation, thereby reducing available oxygen and 


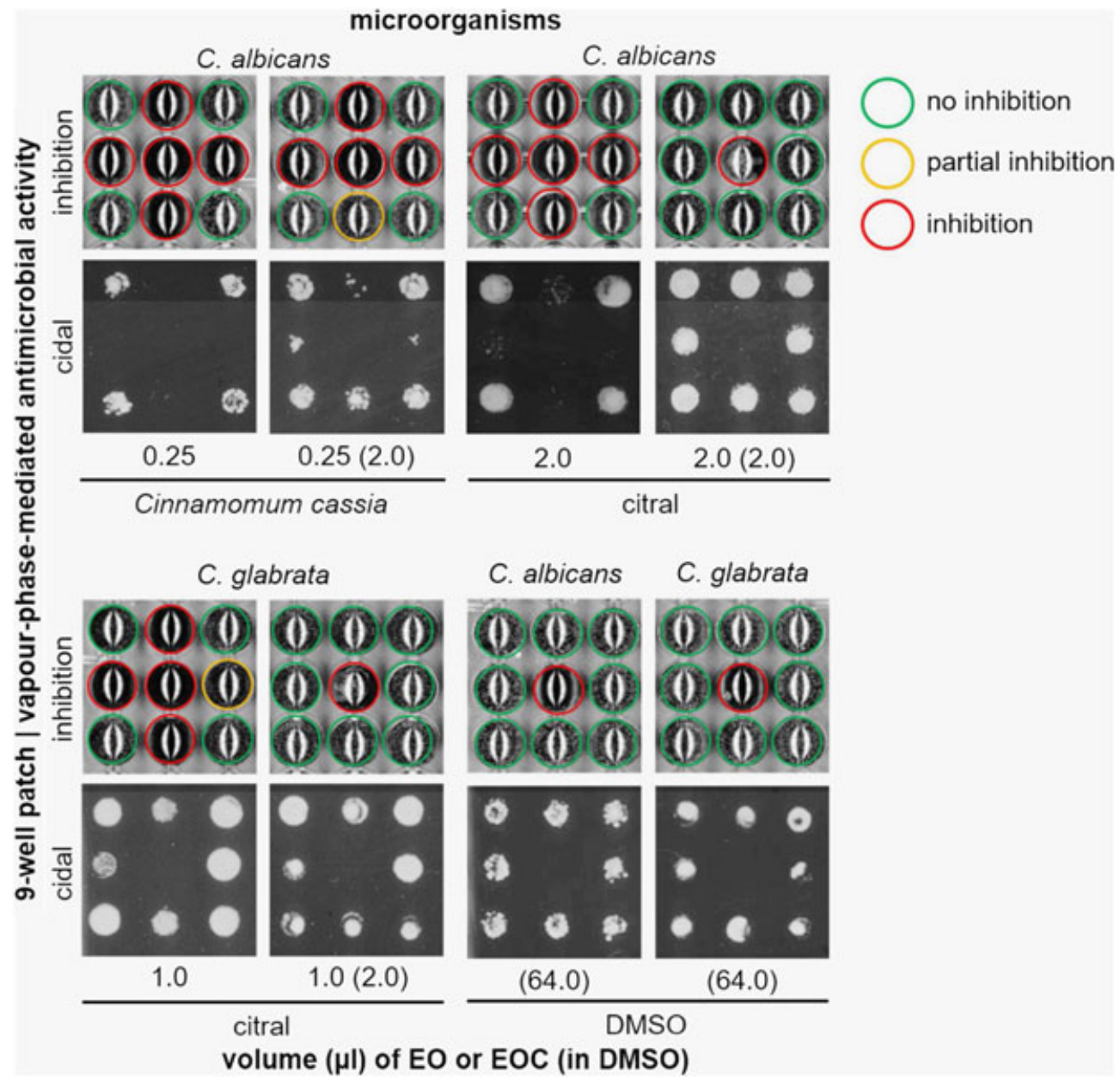

FIGURE 3 Dissolving $\mathrm{EO}(\mathrm{C}) \mathrm{s}$ in DMSO seems to attenuate vapour-phase-mediated antimicrobial activity. Optical scans of 9-well patches of microtitre plates (top rows) and YPD agar plates with spot tests (bottom rows) showing possible growth inhibition and cidal activity respectively, caused by vapour-phase-mediated antimicrobial activity of selected EO(C)s dissolved in DMSO on C. albicans and C. glabrata. Volumes below YPD agar plates with spot tests indicate the quantity of $\mathrm{EO}(\mathrm{C})$ added to the centre well; volumes between brackets indicate the quantity of DMSO used to dissolve the $\mathrm{EO}(\mathrm{C})$ before addition to the centre well

creating a different microenvironment in the sealed wells. The acetate Corning ${ }^{\circledR}$ Cap Mats used in this study were impermeable to $E O(C) s$ and closed off the wells tightly, impeding the evaporation of $\mathrm{EO}(\mathrm{C}) \mathrm{s}$. In contrast, adhesive seals proved insufficient in several of our tests (data not shown), either because the wells were not sealed tightly enough from the start of the experiment or because of the glue loosening over the course of the experiment, resulting in cross-contamination. Thus, even seemingly minor adaptations of reference methods (such as sealing the microtitre plate), can modify the outcome of an experiment.

We therefore adopted an alternative approach that proved successful in practice. Multiple reasons justify this strategy e.g. (i) several types of microtitre plates (e.g. honeycomb plates) do not permit tight closing of the wells, thereby allowing cross-contamination of $\mathrm{EO}(\mathrm{C}) \mathrm{s}$, and (ii) $\mathrm{EO}(\mathrm{C})$ s may interfere with adhesive seals. Our approach does not intrinsically change the CLSI protocol, while at the same time assuring that the experiment is controlled for false positive results caused by possible vapour-phase-mediated antimicrobial activity of $\mathrm{EO}(\mathrm{C})$. It implies adding rows and/or columns of negative controls between the wells containing the $\mathrm{EO}(\mathrm{C}) \mathrm{s}$ to be tested. In this way, $\mathrm{EO}(\mathrm{C}) \mathrm{s}$ with vapour-phase-mediated antimicrobial activity will be detected as growth in adjacent negative control wells will be affected. In most cases, it will be clear from the spatial pattern which $\mathrm{EO}(\mathrm{C})$ is responsible for the vapour-phase-mediated antimicrobial activity. However, if different $\mathrm{EO}(\mathrm{C}) \mathrm{s}$ with vapour-phase-mediated antimicrobial activity would be in close proximity, identifying the causative one(s) might not be straightforward. Therefore, all the $\mathrm{EO}(\mathrm{C}) \mathrm{s}$ near a vapour-phase-mediated antimicrobial activity disturbance should be retested using a different plate lay-out.

In conclusion, we have demonstrated that EOCs of diverse chemical classes i.e. phenols, aldehydes and alcohols, as well as EOs rich in these components, show vapour-phase-mediated antimicrobial activity. Since many of the $\mathrm{EO}(\mathrm{C}) \mathrm{s}$ tested showed this effect, it may be a common characteristic of $\mathrm{EO}(\mathrm{C}) \mathrm{s}$. Hence, it is not a negligible phenomenon and has to be taken into account when planning and designing an experiment with $\mathrm{EO}(\mathrm{C}) \mathrm{s}$. Our proof-ofprinciple study was not intended to exhaustively document this phenomenon for $\mathrm{EO}(\mathrm{C}) \mathrm{s}$. Rather, we aim at providing new tools: (i) an assay to study the vapour-phase-mediated antimicrobial activity of $\mathrm{EO}(\mathrm{C}) \mathrm{s}$ or volatiles in general, and (ii) a microtitre plate set-up allowing researchers to unmask false positive results in a standard MIC screening. 


\section{ACKNOWLEDGEMENTS}

We thank Gert Esseldeurs for excellent technical assistance and Jean-

François Baudoux for his logistical support. This work was supported by grants from the Fund for Scientific Research Flanders (FWO projects WO.009.16 $\mathrm{N}$ and G0D4813N).

\section{REFERENCES}

1. Roemer T, Boone C. Systems-level antimicrobial drug and drug synergy discovery. Nat Chem Biol. 2013;9:222-231.

2. Payne DJ, Gwynn MN, Holmes DJ, Pompliano DL. Drugs for bad bugs: Confronting the challenges of antibacterial discovery. Nat Rev Drug Discov. 2007;6:29-40.

3. Butts A, Krysan DJ. Antifungal drug discovery: Something old and something new. PLoS Pathog. 2012;8: e1002870.

4. Roemer T, Xu D, Singh SB, et al. Confronting the challenges of natural product-based antifungal discovery. Chem Biol. 2011;18:148-164.

5. Balouiri M, Sadiki M, Ibnsouda SK. Methods for in vitro evaluating antimicrobial activity: A review. Chin J Pharm Anal. 2016;6:71-79.

6. CLSI. Reference Method for Broth Dilution Antifungal Susceptibility Testing of Yeasts - Third Edition: Approved Standard M27-A3. Wayne, PA, USA: CLSI; 2008.

7. Palmeira-de-Oliveira A, Salgueiro L, Palmeira-de-Oliveira R, et al. AntiCandida activity of essential oils. Mini Rev Med Chem. 2009;9:1292-1305.

8. Souza CM, Pereira Junior SA, Moraes Tda S, et al. Antifungal activity of plant-derived essential oils on Candida tropicalis planktonic and biofilms cells. Med Mycol. 2016;54:515-523.

9. Adukwu EC, Bowles M, Edwards-Jones V, Bone H. Antimicrobial activity, cytotoxicity and chemical analysis of lemongrass essential oil (Cymbopogon flexuosus) and pure citral. Appl Microbiol Biotechnol. 2016;100:9619-9627.

10. Mikulášová $M$, Chovanová R, Vaverková Š. Synergism between antibiotics and plant extracts or essential oils with efflux pump inhibitory activity in coping with multidrug-resistant staphylococci. Phytochem Rev. 2016;15:651-662.

11. Langeveld WT, Veldhuizen EJ, Burt SA. Synergy between essential oil components and antibiotics: A review. Crit Rev Microbiol. 2014;40:76-94.

12. Doran AL, Morden WE, Dunn K, Edwards-Jones V. Vapour-phase activities of essential oils against antibiotic sensitive and resistant bacteria including MRSA. Lett Appl Microbiol. 2009;48:387-392.

13. Inouye S, Uchida K, Maruyama N, Yamaguchi H, Abe S. A novel method to estimate the contribution of the vapor activity of essential oils in agar diffusion assay. Nippon Ishinkin Gakkai Zasshi. 2006;47:91-98.

14. Kloucek P, Smid J, Frankova A, Kokoska L, Valterova I, Pavela R. Fast screening method for assessment of antimicrobial activity of essential oils in vapor phase. Food Res Int. 2012;47:161-165.

15. Nedorostova L, Kloucek P, Kokoska L, Stolcova M, Pulkrabek J. Antimicrobial properties of selected essential oils in vapour phase against foodborne bacteria. Food Control. 2009;20:157-160.
16. Laird K, Phillips C. Vapour phase: A potential future use for essential oils as antimicrobials? Lett Appl Microbiol. 2012;54:169-174.

17. Underhill DM, lliev ID. The mycobiota: Interactions between commensal fungi and the host immune system. Nat Rev Immunol. 2014;14:405-416.

18. Sardi JC, Scorzoni L, Bernardi T, Fusco-Almeida AM, Mendes Giannini MJ. Candida species: Current epidemiology, pathogenicity, biofilm formation, natural antifungal products and new therapeutic options. J Med Microbiol. 2013;62(Pt 1):10-24.

19. Brunke S, Hube B. Two unlike cousins: Candida albicans and C. glabrata infection strategies. Cell Microbiol. 2013;15:701-708.

20. Suhr MJ, Hallen-Adams HE. The human gut mycobiome: Pitfalls and potentials-A mycologist's perspective. Mycologia. 2015;107: 1057-1073.

21. Mandras N, Nostro A, Roana J, et al. Liquid and vapour-phase antifungal activities of essential oils against Candida albicans and non-albicans Candida. BMC Complement Altern Med. 2016;16:330.

22. Budzyńska A, Sadowska B, Lipowczan G, Kalemba D, Różalska B. Activity of selected essential oils against Candida spp. strains. Evaluation of new aspects of their specific pharmacological properties, with special reference to lemon balm. Adv Microbiol. 2013;3:317-325.

23. Tyagi AK, Malik A. Liquid and vapour-phase antifungal activities of selected essential oils against Candida albicans: Microscopic observations and chemical characterization of Cymbopogon citratus. BMC Complement Altern Med. 2010;10:65.

24. Leite MC, Bezerra AP, de Sousa JP, Guerra FQ, Lima EO. Evaluation of antifungal activity and mechanism of action of Citral against Candida albicans. Evid Based Complement Alternat Med. 2014;2014:378280.

25. Başer KHC, Buchbauer G. Handbook of essential oils : science, technology, and applications. Second edition. ed. Boca Raton: CRC Press, Taylor \& Francis Group; 2016.

26. Franchomme P, Jollois R, Pénoël D, Mars J. L'aromathérapie exactement: encyclopédie de l'utilisation thérapeutique des huiles essentielles: fondements, démonstration, illustration et applications d'une science médicale naturelle. Limoges: R. Jollois; 2001.

27. Hili P, Evans CS, Veness RG. Antimicrobial action of essential oils: The effect of dimethylsulphoxide on the activity of cinnamon oil. Lett Appl Microbiol. 1997;24:269-275.

\section{SUPPORTING INFORMATION}

Additional Supporting Information may be found online in the supporting information tab for this article.

How to cite this article: Feyaerts AF, Mathé L, Luyten W, et al. Assay and recommendations for the detection of vapour-phase-mediated antimicrobial activities. Flavour Fragr J. 2017;1-7. https://doi.org/10.1002/ffj.3400 